\title{
Trabalhando a missão de um hospital como facilitador da mudança organizacional: limites e possibilidades
}

\author{
Developing the hospital's mission to facilitate \\ organizational change: limits and possibilities
}

\footnotetext{
1 Departamento de Medicina Preventiva e Social, Universidade Estadual de Campinas. Cidade Universitária, Campinas, $S P$ 13083-970, Brasil. lcecilio@correio.com.br
}

\begin{abstract}
The author begins by discussing the field of General Administration Theory vis-à-vis the defining role of "organizational goals" within an overall change process in organizations. While admitting the validity of some challenges raised by certain authors who deny the possibility of establishing a "single" direction for the organization by explicitly outlining its formal or official goals, the author presents and discusses his experience in defining the mission in the health sector as a way to implement organizational goals. This definition is meant as a strategy to improve communications among health team members and to a culture of responsibility when dealing with health service users.
\end{abstract}

Key words Organizational Objectives; Organizational Innovation; Organization and Administration

Resumo O autor, inicialmente, apresenta algumas considerações encontradas no campo da Teoria Geral da Administração, sobre o papel da definição de "objetivos organizacionais" em um processo de mudança das organizações em geral. Mesmo reconhecendo a validade de parte do questionamento feito por certos autores que, no limite, negam a possibilidade de se imprimir "uma" direcionalidade para a organização com base na explicitação dos seus objetivos formais ou oficiais, o autor apresenta e discute sua experiência, no setor saúde, de definição da missão (uma forma de "tradução" de objetivos organizacionais) como estratégia de melhorar a comunicação dentro da equipe e da criação de uma cultura de responsabilidade frente ao usuário.

Palavras-chave Objetivos Organizacionais; Inovação Organizacional; Organização e Administração 


\section{Introdução}

Este é um artigo que pretende explorar a possibilidade de conduzir mudanças nas organizações de saúde, a partir da definição e operacionalização compartilhadas entre a direção e os trabalhadores, de um "projeto" para um hospital, traduzido tanto em sua missão institucional, como nas missões das várias unidades operacionais. Cabe, então, uma melhor explicitação de alguns termos apresentados no título.

Estamos denominando de "mudança organizacional" o redesenho das organizações em função das necessidades dos usuários. Um primeiro esclarecimento necessário nesta definição é a respeito do que se entende por necessidades quando estamos trabalhando as organizações de saúde. Com certeza, não há resposta fácil para esta discussão. Há vários trabalhos de autores brasileiros que nos ajudam a lançar alguma luz sobre o tema. Nogueira (1994) aponta para o fato de que, ao se trabalhar as necessidades dos usuários dos serviços de saúde, teremos que considerar a "opinião" do usuário, com seu componente de subjetividade, e também o lado mais "científico", relativo aos saberes dos profissionais de saúde, portanto mais “objetivo" e "verificável”. Já Stotz (1991) e Campos (1991) vão nos lembrar, entre outras coisas, que as necessidades trazidas aos serviços de saúde, apesar de terem uma dimensão ou determinação social mais ampla, apresentam um componente para cada pessoa, que o serviço precisa estar atento e saber interpretar. Cecilio (1999) constrói uma Taxonomia das Necessidades de Saúde bastante eclética, em diálogo com várias "escolas" de pensamento e autores, sugerindo que a mesma funcione como uma espécie de roteiro que deveria ser considerado na organização dos serviços: necessidades de boas condições de vida, ter acesso às tecnologias para melhorar e prolongar a vida, ter vínculo com um profissional ou equipe e ter autonomia no modo de andar a vida. Adotam-se, na construção deste artigo, as idéias desenvolvidas por estes autores.

O outro conceito presente na definição de mudança organizacional adotada e que necessita de melhor esclarecimento é o de "usuário". Há pelo menos dois termos que poderiam ser empregados como seus (quase) sinônimos: o de cliente e o de cidadão. O primeiro utilizado mais na lógica do Mercado, no âmbito da circulação das mercadorias, onde predominam as leis da livre escolha e da relação demanda/oferta. O cliente seria o "consumidor" das empresas privadas, inclusive as prestadoras de serviços de saúde. Por outro lado, o termo cidadão seria compreendido como o "consumidor" dos serviços públicos governamentais, no campo das políticas sociais. O artigo vai assumir o risco de utilizar o conceito de consumidor em sua dupla sinonímia, qual seja, o de cliente e de cidadão, sem desconsiderar as indicações de Vieira (1996) no sentido de reforçar as diferenças entre os dois termos: o conceito de cliente implica a liberdade de escolha e este não é o caso dos usuários dos serviços públicos; assim, o conceito de cliente seria problemático no setor público já que o público em geral é, em última análise, o cliente. É bom que se esclareça, também, que a decisão de adotarmos o conceito de "usuário", tanto no sentido de cliente como de cidadão, não implica uma adesão ao "gerencialismo", ou seja, a aplicação do discurso gerencial à área governamental tal como apontado no projeto de reforma do Estado Brasileiro em curso, onde se imagina que uma das estratégias para a superação dos traços de formalismo e patrimonialismo da burocracia brasileira seria a introdução do conceito de cliente nos órgãos governamentais ou em seus substitutos públicos não governamentais, o chamado "terceiro setor". Poderíamos dizer, então, que a mudança organizacional tratada aqui é aquela que toma o usuário/consumidor dos serviços de saúde, seja ele cliente (do setor privado) ou cidadão (do setor público), com o conjunto de suas necessidades, como o seu vetor principal. Dito de outra forma trata-se, então, de se fazer uma reflexão, a partir da lógica das organizações de saúde, da possibilidade da construção de consensos internos, costurados em torno de um "projeto", entre a direção e os trabalhadores de saúde e as várias categorias de profissionais tão distintas entre si, dando centralidade ao usuário/consumidor dos serviços.

Cabem agora alguns esclarecimentos em relação ao termo "projeto", aqui traduzido como "missão". Um bom sinônimo para "projeto", na forma como é utilizado neste texto, é "objetivo oficial” tal qual usado por Perrow (1978). O autor contrapõe este conceito ao de "objetivos operativos", ou seja, as atividades concretas desenvolvidas por membros ou grupos das organizações. Os objetivos oficiais seriam as proposições gerais da organização, assumidos em manifestações formais e públicas pelos dirigentes. "São propositalmente vagos e genéricos e não indicam os dois maiores fatores que influenciam o comportamento organizacional: as inúmeras decisões que podem ser tomadas entre vias alternativas para alcançar os objetivos oficiais e a prioridade dos objetivos múltiplos, e os muitos objetivos não oficiais perseguidos por grupos dentro da organização" (Perrow, 1978: 
216). No caso dos hospitais, esta contraposição entre objetivos formais, oficiais e aqueles operacionais, implementados por categorias profissionais dotadas de alto grau de autonomia é um tema a ser considerado.

Strauss (1963 apud Carapinheiro, 1993), a partir de considerações construídas no campo do interacionismo simbólico, afirma que haveria tantos projetos ou objetivos em um hospital quantos são os seus atores, de forma que o único "projeto" formal, algo que ele chama de "cimento simbólico" da organização, seria o de que o hospital existe para salvar vidas e minorar o sofrimento humano. Nada mais concreto e detalhado do que isto poderia ser usado como "projeto" aglutinador dos trabalhadores em um processo de mudança organizacional. Silverman (1975) considera quase como uma reificação falar em "objetivos organizacionais" a partir de considerações muito parecidas com as de Strauss.

De qualquer forma, é necessário considerar a idéia de que o estabelecimento de objetivos seria imprescindível para que a ação organizacional não seja fruto do acaso, tem muita força em toda a produção da Teoria Geral da Administração (TGA) e é um tema que tem que ser levado em conta nesta introdução. Podemos encontrar, já em Henry Fayol, no início do século, a preocupação com o tema dos "objetivos" de uma organização, quando ao falar de um dos elementos da administração - a previsão afirma que "o programa de ação é, ao mesmo tempo, o resultado visado, a linha de conduta a seguir, as etapas a vencer, os meios a empregar; uma espécie de quadro do futuro em que os acontecimentos próximos figuram com certa clareza, segundo idéias preconcebidas, e onde os acontecimentos distantes surgem mais ou menos vagos; é a marcha da empresa prevista e preparada para certo tempo" (Fayol, 1968:77). É interessante que, para o clássico autor, a "função administrar", que inclui o elemento previsão (elaborar o projeto de ação) é distinta de dirigir, que é "conduzir a empresa, tendo em vista os fins visados, procurando obter as maiores vantagens possíveis de todos os recursos de que ela dispõe" (Fayol, 1968:22). Há uma relação de subordinação do "administrar" ao dirigir, lugar do efetivo exercício do poder e da definição dos objetivos oficiais da instituição. É possível afirmar que esta concepção fayolista dos objetivos definido "em cima”, pelos níveis superiores de decisão - pela "direção" - e descendo em cascata para os níveis administrativos intermediários, até os níveis operacionais, é ainda paradigmática nas organizações e em boa parte do que se produz TGA, mesmo nas correntes mais contemporâneas como nos programas de gestão da qualidade total.

Para Chiavenato, a Administração por Objetivos (APO) significou uma espécie de revolução copernicana dentro da Administração, ao fazer um deslocamento da atenção colocada nas atividades-meio, no controle sobre a qualificação dos processos para o enfoque nos resultados e objetivos alcançados. "A ênfase em fazer corretamente o trabalho (the best way de Taylor) para alcançar eficiência passou à ênfase em fazer o trabalho mais relevante aos objetivos da organização para alcançar eficácia" (Chiavenato, 1983:241) (grifos meus).

Para o autor a APO é um método onde as metas são definidas em conjunto entre o administrador e seu superior, as responsabilidades são especificadas para cada atividade em função dos resultados esperados, que passam a integrar os padrões de desempenho sob os quais os gerentes serão avaliados. Ao final, o desempenho do gerente pode ser avaliado objetivamente e os resultados atingidos comparados com os esperados (Chiavenato, 1983). Trabalhando com conceitos como "objetivos da empresa”, "objetivos principais da organização” a APO, apesar de ser considerada "uma revolução copernicana”, não consegue superar o paradigma fayolista ao ocultar os verdadeiros objetivos da organização, definidos, no que têm de substantivos, nos "níveis superiores" e portador de uma contradição insuperável: os interesses antagônicos entre o capital e a força de trabalho.

Uma outra possibilidade de definição do "projeto" ou dos objetivos de uma empresa, é o conjunto das "metas organizacionais", consideradas por Etzioni como um estado de coisas que a organização está tentando alcançar, mas alerta para o fato de que nem sempre as metas declaradas são as reais, de forma que "um pesquisador não pode aceitá-las sem críticas como suas verdadeiras metas sociológicas, uma vez que as organizações tendem a sustentar metas 'públicas' para propósitos de 'fachada'. Nem pode o pesquisador extrair essa informação das elites do topo, uma vez que elas podem não estar livres para falar francamente de tais metas" (Etzioni, 1974:106). Esta é a típica perspectiva estrutural, que leva em conta o tema do poder e dos conflitos de interesses no interior das organizações, ao contrário dos autores "clássicos" que têm uma visão mais formalista ou racional da definição de objetivos e tomada de decisões (Vieira, 1999).

Também para Etzioni, em outra obra, "os objetivos são freqüentemente estabelecidos em um complicado jogo de poder, que inclui diversos indivíduos e grupos, dentro e fora da organi- 
zação, através da referência aos valores que dirigem o comportamento em geral e ao comportamento específico dos indivíduos e grupos numa determinada sociedade" (Etzioni, 1964:10). Para ele, "(o objetivo de uma organização) é influenciado, em parte, pelos objetivos dos grandes diretores, pelos da comissão de diretores $e$ pelos dos subordinados. É determinado, às vezes, numa consulta pacífica, às vezes numa luta de poder entre várias divisões, instalações, conspirações, subordinados e 'personalidades' da organização" (Etzioni, 1964:8). Parece que aqui há um claro questionamento do paradigma fayolista, quando há o reconhecimento de que nem sempre há uma confluência automática entre objetivos pessoais ou de grupos e os da organização, algo como o inevitável conflito entre as expectativas e aspirações democráticas dos empregados e sua limitada participação na tomada de decisões.

Hall (1984) questiona a idéia de que a eficácia de uma organização possa ser avaliada pelo grau em que realiza suas metas, como deseja Etzioni. Para ele, as organizações têm objetivos múltiplos e freqüentemente conflitantes. A diferenciação estrutural das organizações está relacionada com a diversidade e a incompatibilidade das metas (Kochan et al., 1975 apud Hall, 1984). Às metas oficiais, Hall (1984) contrapõe a idéia das operacionais não oficiais, mais diretamente vinculadas aos interesses de grupo e, embora possam apoiar, subverter ou ser irrelevantes para as oficiais, não têm uma ligação necessária com estas.

A abordagem de metas apresenta ainda outras complicações. Em sua forma mais simples, o modelo mostra que, se uma organização tem uma certa meta, ela se organizará de tal maneira que possa maximizar ou otimizar sua consecução. É bem sabido, hoje em dia, que há limitações na racionalidade dos atores humanos e que as decisões dentro das organizações tendem a estar em nível abaixo do ótimo, como nos alertam March \& Simon (1970) em trabalho já clássico. "Mesmo com estas restrições, presume-se, geralmente, que as organizações operam conforme normas de racionalidade. A complicação é que, o que deveria ser, pelo menos, minimamente racional em um momento, pode não sê-lo no outro" (Hall, 1984:194).

Outro problema ou dificuldade de se trabalhar com metas é que há uma tendência de se trabalhar com aquelas facilmente quantificáveis às custas das que não o são. Basta lembrar o exemplo das universidades, que consideram o número de publicações do corpo docente e não a meta do ensino em sala de aula, que é mais difícil de medir.
Apesar dessas dificuldades, autores como Hannan \& Freeman (1977 apud Hall, 1984) acham que seria inadequado abandonar totalmente o conceito de meta, uma vez que elas seriam parte das características definitórias de uma organização. Defendendo, também, que a idéia de metas pode e deve ser trabalhada na organização, Hall (1984) afirma que os responsáveis organizacionais pelas decisões (na verdade todos os seus integrantes) criam, de fato, a realidade das situações enfrentadas pelas organizações, em suas próprias mentes. Parte da construção da realidade inclui conjuntos de idéias sobre o rumo que a organização está tomando. Isso se mescla com o processo decisório.

O que se quis cumprir nesta introdução foi, além de um esclarecimento dos termos utilizados no artigo, tentar circunscrever a "ferramenta gerencial”, que é o trabalho com a missão das organizações de saúde na moldura do debate teórico muito pertinente ao existente no campo da TGA, a respeito da legitimidade ou potência de se trabalhar com uma definição precisa de "objetivos organizacionais", de forma explícita e sistematizada. Dito de outra forma poderíamos terminar esta introdução com uma indagação: a missão, tal qual definida em programas de mudança organizacional, não poderia ser vista como um "objetivo oficial”, formal, da direção superior, com pouca possibilidade de aglutinar os trabalhadores ou coalizões de profissionais de saúde, com forte tradição de autonomia na operacionalização de múltiplos objetivos? Esta é a questão central para a qual tentaremos apontar algumas respostas no correr deste artigo.

\section{A definição dos objetivos das organizações de saúde como disparador de mudanças: trabalhando a missão institucional}

A brevíssima revisão da temática "definição de objetivos” no campo da TGA, na introdução, já é suficiente para nos alertar sobre os problemas na sua concepção e operacionalização. Essas dificuldades poderiam ser simplificadamente apresentadas assim:

- Os objetivos formais ou oficiais de uma organização parecem ser portadores, sempre e de uma forma congênita, de uma ambigüidade que se traduz em um jogo de transparências e opacidades, de ditos e não-ditos, de um lado público e outro "privado" (a pessoas ou grupos). Nessa medida, pesaria sobre os objetivos formais de uma organização a pecha de "falsidade" ou, melhor dizendo, de pouca credibili- 
dade. Algo "para inglês ver". Ou, no mínimo, algo tão genérico que todos acabam concordando com seu enunciado. Algo que não seria para valer.

- Nas organizações existiriam tantos "projetos” quantos são os seus atores ou suas coalizões de poder, de forma que um objetivo formal, no limite, seria uma reificação. Aliás, para autores como Silverman (1975) as "organizações”, como as pensamos no senso comum, também seriam, elas próprias, reificações!

Mesmo com tais limitações e dificuldades, a idéia de se trabalhar com um "projeto", nos seus múltiplos sentidos de missão ou plano, ou definição de metas, ou de imagem-objetivo, diretrizes e outros conceitos que "definam um rumo", tem muita força no imaginário dos gerentes e dirigentes do setor saúde.

A idéia de operacionalizar o conceito de missão nas organizações de saúde foi amadurecendo a partir da experiência do autor de trabalhar com o planejamento estratégico em organizações governamentais de saúde. A metodologia de planejamento adotada era centrada na problematização situacional (Matus, 1993) feita por atores institucionais. Em mais de uma situação, em realidades bem distintas, em vários pontos do Brasil, o resultado dessa etapa de problematização era sempre muito parecido: o foco de atenção eram os problemas intermediários vividos na organização. Exemplos de tais problemas: falta de pessoal, profissionais despreparados, falta de recursos financeiros, pouca autonomia administrativa dos gestores, o poder médico na equipe, despreparo gerencial, falta de planejamento e outros. É impressionante a regularidade da pauta de problemas levantados em tantas organizações governamentais diferentes, do norte ao sul do país! Poder-se-ia dizer que há uma matriz discursiva bem regular dos gestores do setor saúde e dos dirigentes dos serviços, que é o discurso da impotência, do andar em círculos em torno dos mesmos problemas. Sempre questões intermediárias e quase nunca problemas vividos pelas pessoas reais que buscam os serviços.

Havia, e há, por parte dos dirigentes, gerentes e trabalhadores que participavam dessas oficinas de planejamento, uma enorme dificuldade em enxergar o outro, aquele que demanda o serviço, aquele que busca a organização com necessidades que, supõe, esta possa resolver: o usuário. Há como uma fixação "no próprio umbigo", para usar uma expressão da linguagem comum. Os dirigentes e/ou gerentes públicos parecem sofrer de uma cegueira ou, no mínimo, uma dificuldade imensa de entender a finalidade da organização, sua singulari- dade enquanto produtora de determinados serviços, seu compromisso social. No caso do setor governamental, muito do seu desgaste advém desta postura de insensibilidade perante o usuário e a conseqüente dificuldade de viabilizar estratégias de humanização e qualificação do atendimento.

Por tudo isso, a centralidade que o conceito de cliente tem na definição da missão, tal qual trabalhado há vários anos no setor privado e em (raríssimos) órgãos públicos, pareceu ser uma indicação a ser explorada com mais atenção nas organizações de saúde. O conceito de missão foi muito popularizado nos últimos anos, em nosso país, pelos "programas de qualidade total". Ele é uma espécie de ponto de partida que, tomando o cliente com foco de atenção, vai abrindo toda a função gerencial e (re)organizando o processo de trabalho. No caso específico do setor governamental, a definição da missão poderia ser vista como uma mediação entre diretrizes muito amplas das políticas de saúde vigentes e o processo de organização dos processos de trabalho. Onocko (1998) aponta para isto ao mostrar a relação entre o desenho de "imagens-objetivo" das várias unidades de um hospital psiquiátrico e as diretrizes da reforma psiquiátrica. Assim, ainda no caso do setor governamental, a missão poderia ser experimentada como uma mediação, uma aproximação, entre as diretrizes de construção da cidadania que explícita e implicitamente estão contidas na legislação que regulamenta o Sistema Único de Saúde (SUS) e a realidade concreta das organizações. Eis aí, então, algumas razões para se pensar na adoção de idéia da definição da missão para as organizações de saúde: uma maneira de provocar um deslocamento do olhar, do foco de atenção das equipes de saúde para o usuário e uma forma de ir traduzindo diretrizes muito genéricas para a vida real das organizações e de seus usuários.

Uma primeira preocupação que se teve quando se iniciou a utilização da idéia de missão nas organizações (governamentais) de saúde - em função da experiência do autor no setor público - foi a de verificar se era possível (factível) definir claramente as missões dos vários departamentos ou serviços (unidades operacionais) e da organização como um todo. Se, diante da complexidade dessas organizações, seria possível encontrar uma formulação-síntese que caracterizasse a singularidade, traduzida na missão, por exemplo, de um pronto-socorro. Não só foi possível, como tem sido surpreendente o "potencial comunicativo" que existe nesse momento de formulação da missão. É possível adiantar, também, que o fato do 
conceito de missão e clientes serem, numa primeira aplicação, operacionalizáveis, isto é, "aplicáveis” nas organizações de saúde, não significa que não existam outras dificuldades na sua utilização concreta, como veremos adiante.

As missões das organizações de saúde têm sido construídas com a preocupação de que possam explicitar, sem ambigüidade, quatro conceitos que deixem claro sua singularidade e seu compromisso com a sociedade: esta organização existe para oferecer tais produtos, com tais características, para tais clientes visando alcançar tais resultados. Este é o enunciado da missão. Ela pode ser formulada tanto para a organização como um todo, um hospital, por exemplo, como ela pode ser formulada para cada departamento ou serviço. Mesmo em um centro de saúde pode-se trabalhar a missão de cada equipe, tais como a de adulto, a da saúde da mulher, a da sala de vacina. As missões das “partes” devem manter uma relação de coerência e complementariedade com a missão do "todo", no caso, a organização.

Como foi dito, a primeira preocupação, ao se adotar a missão como instrumento ou ferramenta de gestão, foi sobre sua aplicabilidade às organizações. O conceito é perfeitamente aplicável ao setor de saúde e apropriado com muita clareza pela equipe. Além do mais, por meio da experiência do autor, é possível apontar alguns ganhos após a explicitação da missão:

- É um dispositivo para a conversação e o agir comunicativo tal como desenvolvido por Rivera (1995), a partir das formulações habermasianas. É um instrumento para "costura” de consensos junto a equipes tão diversificadas e com tanta assimetria de poder como são as da saúde, no sentido dado por Offe: "a tarefa de obter consenso e harmonizar interesses se coloca para a administração, não só quando se torna necessário abrandar pela negociação a resistência de grupos antagônicos com poder de veto e pressão, mas também em relação com sua própria clientela ou ainda na relação com seu meio ambiente interno (grifo original), os membros da administração com seus interesses e concepções de valor, de ordem profissional, econômica e política" (Offe, 1984 apud Rivera, 1995:109).

- Estimula um deslocamento da atenção das equipes de seus problemas internos para o cliente, o que representa, por si só, um dispositivo importante de mudança na cultura dominante nos órgãos governamentais. Muitos gerentes e equipes se surpreendem, no processo de formulação da missão, com o fato de que nunca pensaram nos usuários com materialidade e centralidade, no sentido de pessoas reais com necessidades que o serviço pode, em graus variados, atender. Trabalhar com missão ajuda a colocar o "outro" na agenda dos trabalhadores de saúde.

- Esclarece, para os trabalhadores, a singularidade da organização e sua responsabilidade social, com forte ênfase no alcance de determinados resultados.

- Alimenta o processo de planejamento, facilitando a percepção dos problemas finais, ou seja, aqueles vividos pelos usuários. Desloca a atenção dos problemas intermediários. As dificuldades no cumprimento da missão orientam a formulação do planejamento estratégico. A missão é a expressão mais concreta dos objetivos da organização.

- Estimula o uso criterioso de informações e a criação de indicadores que possibilitem o acompanhamento do desempenho da organização, inclusive pelos usuários nas suas várias instâncias de representação. Estes indicadores podem ajudar a abrir a "caixa-preta" das organizações, permitindo um maior controle daqueles sobre estas. Apesar desses ganhos, ou possibilidades de ganhos, que a adoção da missão como ferramenta gerencial tem propiciado, persistem problemas que merecem uma melhor investigação:

a) O "objeto" das organizações de saúde pode, em algumas situações, ser de difícil medição. Nas áreas assistenciais, em particular, a qualidade do "produto" oferecido (na verdade, serviços) é um complexo procedimento que inclui não só medições objetivas, "parametrizadas", como deve considerar um forte elemento de subjetividade por parte do usuário. Examinemos o exemplo de um serviço de obstetrícia cujo produto principal (definido em sua missão) seja "oferecer assistência ao parto com excelência técnica, humanismo e ética”. A excelência técnica pode ser medida com indicadores do tipo taxa de cesárea, a mortalidade materna, a mortalidade perinatal, só para ficar com os mais "clássicos". Como se mede, porém, que este atendimento foi realizado com "humanismo e ética?" Quem mede isso? Como se supera uma relação de assujeitamento da usuária em relação à equipe, no sentido de ser possível estabelecer uma relação mais horizontal e "comunicativa" - no sentido habermasiano no momento da entrevista? Por outro lado, os "resultados" expressos na missão, no caso da saúde, são também muito complexos e dependentes de tantos fatores intervenientes, que fica difícil medir o quanto a equipe contribuiu ou deixou de contribuir para o seu alcance.

b) Nem sempre há informações "quentes" (confiáveis, ágeis e facilmente disponíveis) para a montagem dos indicadores. Freqüente- 
mente as organizações lidam com montanhas de dados, quase sempre colhidos de forma mecânica, burocratizada e desqualificada, mas dispõem de poucas informações "quentes" para o processo gerencial. Trabalhar com missão implica, então, em uma mudança radical na forma como nossas organizações geram, processam e distribuem a informação.

c) Para além dos dois problemas apontados acima, a complexidade do objeto da saúde e a dificuldade de se obter informação de boa qualidade, há ainda uma questão de ordem mais geral muito bem apontada por Etzioni (1989) e que deve ser considerada no caso das organizações de saúde: quase todas as organizações, sob pressão da racionalidade, tornam-se impacientes para medir sua competência. Curiosamente, esse esforço - o desejo de verificar nossa posição e de encontrar maneiras de melhorar, se não estivermos tão bem quanto deveríamos - apresenta, muitas vezes, resultados indesejáveis, do ponto de vista dos objetivos da organização. A mensuração freqüente pode deformar os esforços da organização porque, geralmente, alguns aspectos são mais mensuráveis do que os outros. A verificação freqüente tende a encorajar a superprodução de itens de fácil medição e o descaso pelos dificilmente mensuráveis (Etzioni, 1989). Esse fato já tem sido observado na experiência do autor, tanto em hospitais como em centros de saúde. Etzioni (1989) dá o exemplo das escolas que medem a qualidade dos seus currículos pelo número de alunos que passam nos exames vestibulares, descuidando-se do "desenvolvimento do caráter dos alunos", coisa, sem dúvida, de "mensuração" mais difícil.

No próximo item, é feita uma avaliação mais detalhada das implicações ou, dos limites e possibilidades de operacionalização da missão em um serviço concreto, no caso, a unidade de obstetrícia de um hospital municipal. Vamos ao exercício.

\section{Alguns desdobramentos da utilização da missão em uma unidade hospitalar}

O que se apresenta, agora, é uma "simulação" da utilização da missão em um serviço imaginado, uma espécie de "tipo ideal" dos serviços de obstetrícia existentes nos hospitais governamentais de porte médio. O que se quer testar neste exercício é a sua aplicabilidade, que outros dispositivos ou "ferramentas gerenciais" precisam ser utilizadas de forma complementar e o quanto pode contribuir para processos de mudanças.
Podemos formular agora, de forma mais cuidadosa, o que seria a missão de um serviço de obstetrícia: "Oferecer assistência ao parto e às intercorrências da gravidez, com excelência técnica, ética e humanidade, de forma universal, para as mulheres da cidade $X$, visando a proteção da maternidade e a redução dos riscos dos recém-nascidos”. É claro que a formulação da missão poderia ser feita de outras maneiras, com outras palavras, porém, esta formulação que se apresenta pode ser considerada bem feita ou "completa" porque dá conta dos elementos que se supõe serem essenciais na missão:

- Produtos: Assistência ao parto e intercorrências da gravidez (procedimentos de parto normal, parto cirúrgico, curetagens em caso de aborto, etc.). Não há necessidade de listar todos os procedimentos (produtos) na formulação da missão pois, em dadas situações, esta listagem ficaria muito longa. No nosso caso, a idéia de "prestar assistência ao parto e às intercorrências da gravidez" já abrange todos esses procedimentos para a equipe da maternidade, à medida que esta se encontra "em situação". Vale destacar que, nas áreas assistenciais dos hospitais, os produtos são sempre serviços. No entanto, os produtos de algumas áreas podem ser bens de consumo, tais como medicamentos, refeições, material de limpeza, etc.

- Características do produto: excelência técnica, tratamento ético e humanizado. A missão não detalha o que seja "excelência técnica" ou "tratamento ético". Este será um desdobramento gerencial posterior da maior importância para ser desenvolvido no espaço da equipe.

- Clientes: toda e qualquer mulher do município $X$, sem qualquer forma de discriminação por tipo de convênio ou forma de pagamento. Este é um dos aspectos da missão que singularizam a missão de um hospital governamental: a universalidade do atendimento. Este tema dos clientes quase sempre é ocultado ou, pelo menos, não explicitado, nas missões dos hospitais que trabalham com segmentação de clientela. Dificilmente uma maternidade poderá trabalhar apenas com mulheres do município $X$, pois, com certeza, deverá atender mulheres dos municípios vizinhos que não dispõem de maternidade. Talvez o correto fosse explicitar, na missão, que a maternidade atende mulheres do município $X$ e região. Veremos a importância deste aspecto da missão no atual estágio de financiamento do SUS no nosso país, em particular para os hospitais públicos ou para os contratados.

- Resultados: maior proteção à maternidade e redução dos riscos dos recém-nascidos, tanto 
em relação à mortalidade como em relação à ocorrência de morbidade relacionadas ao parto (traumatismos, paralisia cerebral, patologias hematológicas, etc.). Claro que não é necessário fazer uma listagem extensa de todas as possibilidades de patologias ou riscos tanto para a mãe quanto para a criança, pois isto o grupo também sabe e deverá ser tema para as conversações e contratos entre a equipe.

Pode-se ver, até aqui, duas coisas muito importantes: a idéia de missão é, como já tinha sido dito antes, perfeitamente "aplicável" em um serviço de saúde tomado como exemplo e, segundo, como está criado um campo de conversações muito fértil no interior da equipe para a implementação da missão. Este último ponto nos faz interrogar, de cara, sobre o sistema de gestão adotado no hospital. Adianta-se, agora, a idéia de que sistemas de gestão mais descentralizados, dirigidos de forma mais colegiada, com gerência profissionalizada, conforme trabalhados por Campos (1992) e Cecilio (1994), são facilitadores do trabalho com a missão e com o compromisso com a qualidade dos produtos consumidos pelos clientes. Isto porque, como se mostra na seqüência, a operacionalização efetiva da missão implica em uma série de desdobramentos na equipe, basicamente de conversações e estabelecimento de compromissos, que são muito facilitados quando a gestão é de molde mais democrático e participativo, tendendo a se constituir em um "sistema de direção de alta responsabilidade" como formulado por Matus (1993).

Falou-se muito, até aqui, de conversações no interior da equipe, porque este é o melhor caminho - ou será único? - para ir fazendo a necessária decodificação da missão em linhas de atuação que orientem o cotidiano das equipes. É esta possibilidade (e necessidade) de desdobramento da missão em linhas concretas de atuação, implementadas e monitoradas em um bom sistema de gestão, que a faz uma boa expressão dos objetivos de uma organização ou de um serviço. Já este primeiro momento, o da definição da missão, pode ser imensamente rico se for compartilhado com o maior número possível de trabalhadores, num processo de construção coletiva e compartilhada. O que não pode acontecer agora - e que acontece freqüentemente - é a "missão" ser enquadrada em uma linda moldura e ir enfeitar a parede do gabinete do diretor! É preciso haver novos esforços na direção da mudança organizacional: a organização comprometida com seus clientes.

A segunda "etapa”, uma vez definida a missão, é estabelecer, com o envolvimento dos trabalhadores, os indicadores que serão usados para monitorar o cumprimento da missão. Agora, deverão ser construídos indicadores para avaliar aspectos do produtos e suas características, o tipo de clientela atendida e o grau de alcance dos resultados. O que se apresenta, a seguir, é um esforço intelectual na construção desses indicadores no exemplo que está sendo trabalhado. Avaliam-se, também, as dificuldades e facilidades nessa construção.

Os indicadores para acompanhamento do oferecimento de produtos com determinadas características definidas na missão já foram delineados antes e são razoavelmente simples, no que diz respeito à excelência técnica, à medida que há inegável consenso de que uma boa maternidade, do ponto de vista da excelência técnica, apresenta taxas de partos cirúrgicos (cesáreas) dentro de determinados padrões aceitos, garante a presença do pediatra na sala de parto, o alojamento conjunto e desenvolve atividades educativas para estimular o aleitamento natural. Outros indicadores para medir a qualificação técnica da assistência poderão ser criados pela equipe de acordo com o grau de complexidade da maternidade. Esses indicadores são de fácil mensuração e construídos a partir de dados secundários, coletados rotineiramente, mas nem sempre utilizados como informação gerencial.

As coisas começam a ficar um pouco mais complicadas quando a equipe passa a discutir as outras características do produto, além da excelência técnica: o atendimento ético e humanizado. Essa discussão, por si só, pode ser vista como um poderoso dispositivo para a equipe refletir e tentar operacionalizar formas concretas de melhoria do serviço. A forma mais tradicional e experimentada de avaliar essas características é a aplicação de questionários no momento da alta, com itens específicos que tentem captar como a cliente se "sentiu" durante o atendimento: se teve sua privacidade respeitada, se esteve informada dos procedimentos, se sentiu a família próxima, etc. Há muitos problemas na aplicação, avaliação e utilização dos dados que emergem nesses questionários, mas é um instrumento gerencial de muita valia. A sensibilidade desses questionários varia muito de acordo com a forma como são aplicados, que pode variar desde os tradicionais impressos, preenchidos pelo próprio paciente e depois "colocados em uma urna", até dinâmicas em grupo com as mulheres no momento da alta, coordenadas por profissionais qualificados. Pode-se ver, então, que há formas muito diferenciadas de se tentar captar a percepção mais subjetiva do usuário, cada qual com grau variado de sensibilidade. 
A avaliação do tipo de clientela que está sendo atendida na maternidade vai gerar um tipo de informação que deve ser apropriada, não só pela equipe, como pela direção superior do hospital para, por exemplo, obtenção de recursos junto ao gestor local do SUS. No caso das maternidades que trabalham com "clientela segmentada”, há interesse em se conhecer os tipos de convênios atendidos; mas é interessante saber a distribuição da clientela por residência, em particular se dentro ou fora do município, o número de consultas de pré-natal realizadas e outras que a equipe definir como importantes. Interessa, aqui, conhecer quem a maternidade está atendendo, se são os clientes esperados na missão e quais as características destes, para a alimentação de novas estratégias. Saber o percentual de mulheres de outros municípios pode ser um importante elemento para negociação de mais recursos - mais Autorizações de Internação Hospitalar (AIHs), por exemplo - junto aos gestores dos recursos do SUS.

Finalmente, cumpriria estabelecer indicadores para avaliar se os resultados previstos na missão estão sendo alcançados. Aqui também poderiam ser utilizados, basicamente, alguns indicadores tradicionais como a taxa de infecção hospitalar, a taxa de mortalidade materna e a de mortandade perinatal por causas ligadas ao parto. Neste caso, em particular, a avaliação do alcance dos resultados está bem fácil, "estruturada”, podendo ser feita a partir de dados secundários. Em alguns casos, os resultados esperados são mais amplos ou mais "vagos" e, portanto, de mensuração mais difícil. Um exemplo: no caso do laboratório, cuja missão é "produzir exames complementares com excelência técnica (....) visando contribuir para a qualidade do atendimento médico", o resultado não só é de mais difícil avaliação, como depende de tantos outros fatores que escapam do escopo específico do laboratório.

Estes indicadores desdobrados da missão guardam uma relação entre si, como se fossem os componentes de uma "árvore de resultados", a imagem invertida de uma "árvore de problemas” (campo 1 da Figura 1). É uma espécie de cartografia da missão decodificada, constituindo um campo para conversações entre a equipe. A missão "traduzida" em resultados concretos que deverão ser alcançados através do processo gerencial e das modificações nos processos de trabalho (campo 2 da Figura 1).

Por tudo o que foi dito, até agora, trabalhar a missão de uma organização pode ser um disparador de mudanças na organização em fun-

Figura 1

O fluxograma dos indicadores desdobrados da missão e sua relação com o processo de trabalho.

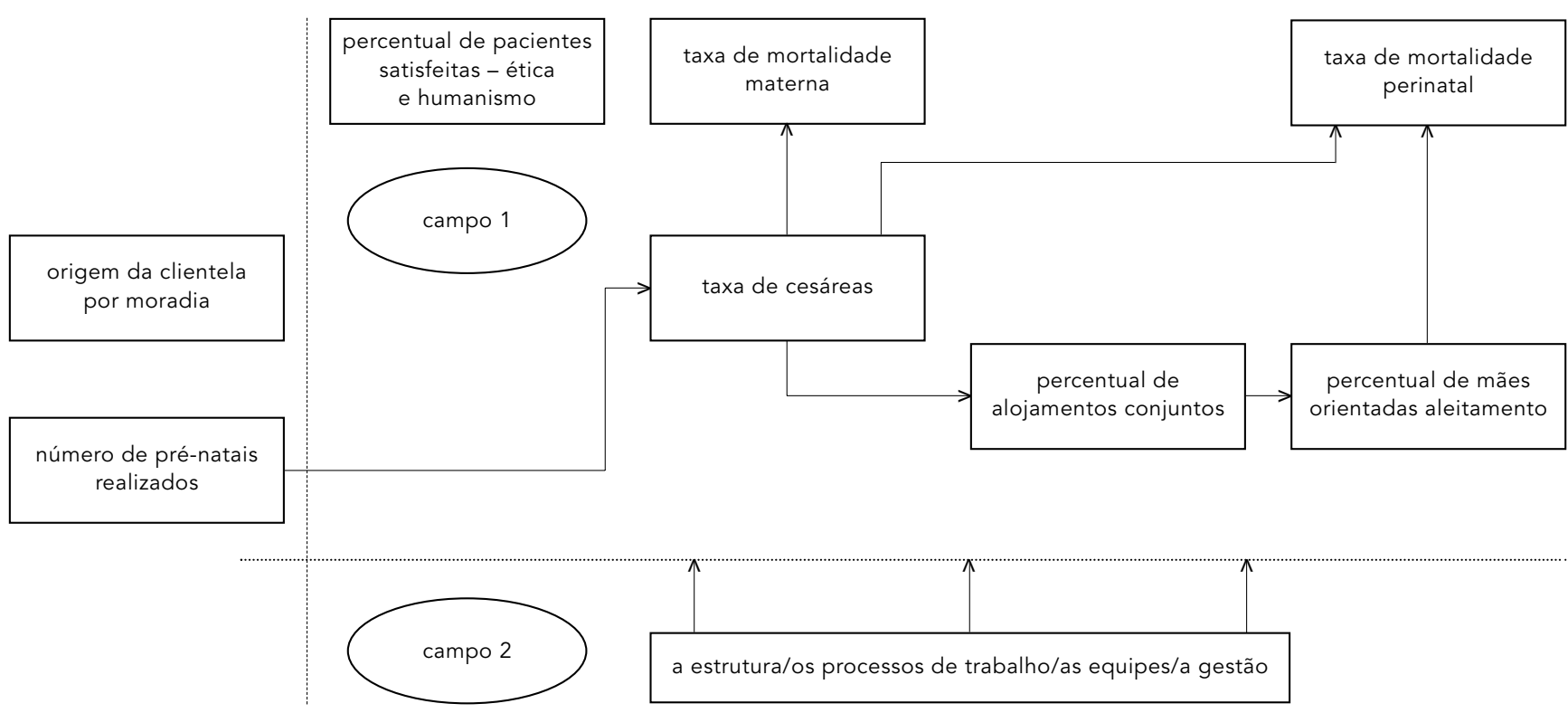


ção, principalmente, de poder constituir um campo de conversações para a equipe. Agora, o campo 1 tem de estar, necessariamente, articulado ao campo 2, o espaço da gestão na sua dobra com os processos de trabalho. Sem esta articulação o campo 1 se esteriliza e a idéia do trabalho com missão pode se transformar em mais um ritual dentro da organização. No fluxograma graficado no campo 1 , podemos ver indicadores de resultados na sua parte mais superior (a satisfação do usuário, e as taxas de mortalidade) e indicadores de processo na parte mais inferior, em que se fala, claramente, de rotinas e modos de organizar a atenção (taxa de cesáreas, o percentual de recém-nascidos que são alojados com a mãe, o percentual de partos que contam com pediatras na sala, etc.). Do campo 2 poderão "emergir" outros indicadores de processo e mesmo de estrutura. A construção desses indicadores - novos instrumentos de avaliação e facilitadores de novos contratos dentro da equipe - deverá se dar no bojo de um processo de planejamento participativo e democrático envolvendo o máximo de trabalhadores.

Trata-se, então, de se adotar um processo gerencial tal que dispositivos (novos arranjos organizacionais e novas ferramentas) sejam criados e testados no desafio da explicitação de uma complexa rede de problemas e de resultados, traduzidos em indicadores sempre construídos por coletivos que os explicitam e os avaliam, tornando cada vez mais "publicizado" o processo de gestão e a trama dos processos de trabalho. Tarefa difícil, essa. Primeiro, porque demanda tempo a construção de um coletivo comprometido com essa forma de funcionamento. Segundo, porque os gerentes dessa gestão hão de ser "construídos em processo", precisam ser "inventados". Terceiro, porque o campo 2 é o dos conflitos, do atravessamento de múltiplos projetos portados por tantos atores e o que está sendo discutido aqui é justamente o desafio de se construir um "projeto" da organização, pelo menos, estabelecer novas bases contratuais que dêem centralidade para os usuários. A mudança pretendida.

"Abrir" o campo 2, aquele da dobra da gestão com os processos de trabalho, implica enfrentar temas como a "governabilidade" do gerente e da equipe para conduzir as mudanças, enfrentar as tensões entre os vetores de autonomia versus o do controle e renegociar a inserção de cada um dos profissionais no interior da equipe.

Voltando ao início do artigo, e como forma de conclusão, a missão, se bem trabalhada em um bom sistema de gestão, poderia contribuir para qualificar o atendimento prestado pelas organizações de saúde. Não é demais reforçar que, a forma como se apresentou o trabalho com a missão neste artigo, significa um total distanciamento da perspectiva formalista ou racional das "escolas" clássicas da TGA, ou seja, aquela que tem a pretensão de ser possível a definição de objetivos de cima para baixo para serem cumpridos pelas "bases" da organização. Pelo contrário, advogamos a adesão à perspectiva que trabalha as organizações como palco de disputa e de interesses distintos, que deverão ser permanentemente negociados em arranjos institucionais que favoreçam a negociação e a disputa.

A aposta que se faz é que a preocupação com o outro, a avaliação permanente de sua satisfação "contamina”, ou melhor, passa a ser imanente ao processo de gestão e dá o eixo para os processos de conversação na equipe. Trabalhar com a idéia de missão, nas organizações de saúde, poderia contribuir para uma profunda mudança cultural, se os coletivos pudessem incorporar a idéia de que cotas maiores de uma vida melhor para todos, dependessem da forma como se articulam as relações entre trabalhadores e usuários; da forma como se articulam os interesses, expectativas e desejos de uns e de outros. 


\section{Referências}

CAMPOS, G. W. S., 1991. A Saúde Pública e a Defesa da Vida. São Paulo: Editora Hucitec.

CARAPINHEIRO, G., 1993. Saberes e Poderes no Hospital: Uma Sociologia dos Serviços Hospitalares. Porto: Editora Afrontamento.

CECILIO, L. C. O., 1999. Programa UNI: Uma necessária ampliação de sua agenda. In: A Educação dos Profissionais de Saúde na América Latina: Teoria e Prática de um Movimento de Mudança. (M. Almeida \& M. Feuerwerker, org.), pp. 129-136, São Paulo: Editora Hucitec.

CHIAVENATO, I., 1983. Introdução à Teoria Geral da Administração. São Paulo: McGraw-Hill.

ETZIONI, A., 1974. Análise Comparativa de Organizações Complexas. São Paulo: Edusp/Rio de Janeiro: Zahar.

ETZIONI, A., 1989. Organizações Modernas. São Paulo: Pioneira.

FAYOL, H., 1968. Administração Industrial e Geral. São Paulo: Editora Atlas.

HALL, R. H., 1984. Organizações: Estrutura e Processo. 3a Ed. Rio de Janeiro: Prentice Hall do Brasil.

MARCH, J. G. \& SIMON, H. A., 1972. Teoria das Organizações. Rio de Janeiro: Fundação Getúlio Vargas.

MATUS, C., 1993. Política, Planejamento e Governo. Brasília: Instituto de Pesquisa Econômica e Aplicada.
NOGUEIRA, R. P., 1994. Perspectivas da Qualidade em Saúde. Rio de Janeiro: Qualitymark.

ONOCKO, R. T., 1993. O Planejamento no Divã ou Análise de uma Ferramenta na Gênese de uma Mudança Institucional. Dissertação de Mestrado, Campinas: Departamento de Medicina Preventiva e Social, Faculdade de Ciências Médicas, Universidade Estadual de Campinas.

PERROW, C., 1978. The analysis of goals in complex organizations. In: Human Service Organizations (Y. Hasenfeld \& R. A. English, eds.), pp. 63-95, Ann Arbor: University of Michigan Press.

RIVERA, F. J. U., 1995. Agir Comunicativo e Planejamento Social: Uma Crítica ao Enfoque Estratégico. Rio de Janeiro: Editora Fiocruz.

SILVERMAN, D., 1975. Teoría de las Organizaciones. Buenos Aires: Ediciones Nueva Visión.

STOTZ, E. N., 1991. Necessidades de Saúde: Mediações de um Conceito (Contribuição das Ciências Sociais para a Fundamentação Teórico-metodológica de Conceitos Operacionais da Área de Planejamento em Saúde). Tese de Doutorado, Rio de Janeiro: Escola Nacional de Saúde Pública, Fundação Oswaldo Cruz.

VIEIRA, M. M. F. \& OLIVEIRA, L. M. B., 1999. Administração Contemporânea: Perspectivas Estratégicas. São Paulo: Editora Atlas. 